\title{
Infestações de Meloidogyne exigua em clones asiáticos de seringueira no Mato Grosso, Brasil
}

\author{
José Carlos Pezzoni Filho ${ }^{1}$, Andressa Lima Brida ${ }^{1}$, William Hiroshi Suekane Takata $^{2} \oplus$, \\ Silvia Renata Siciliano Wilcken ${ }^{1} \mathbb{0}$, Edson Luiz Furtado ${ }^{1}[$
}

'Faculdade de Ciências Agronômicas (FCA), Universidade Estadual Paulista “Julio de Mesquita Filho” (UNESP), Fazenda Lageado, Rua José Barbosa de Barros, $n^{\circ}$ 1780, CEP 18610-307, Botucatu, SP, Brasil; ${ }^{2}$ Universidade do Oeste Paulista (UNOESTE), Rodovia Raposo Tavares, Km 572 - Bairro Limoeiro Cep 19067-175, Presidente Prudente, SP, Brasil.

Endereço para correspondência: José Carlos Pezzoni Filho (jpezzoni@gmail.com)

Data de chegada: 14/12/2016. Aceito para publicação em: 30/01/2019.

$10.1590 / 0100-5405 / 173421$

\section{RESUMO}

Pezzoni Filho, J.C.; Brida, A.L.; Takata, W.H.S.; Wilcken, S.R.S.; Furtado, E.L. Infestações de Meloidogyne exigua em clones asiáticos de seringueira no Mato Grosso, Brasil. Summa Phytopathologica, v.45, n.3, p.326-331, 2019.

O cultivo de seringueira apresenta entre os problemas fitossanitários a incidência do nematoide das galhas, mais especificamente o Meloidogyne exigua raça 3, demonstrando relevante importância para a cultura, fato constatado na presente avaliação, pois levou ao abandono do plantio. Neste experimento foi avaliada a infestação de M. exigua em plantio de seringueira, sem identificação do porta-enxerto, nas raízes e no solo, nos clones GT 1, PR 255, PB 235, PB 217 e RRIM 600 e, foi verificada as infestações entre os clones/ enxertos e, entre populações avaliadas em dois períodos do ano de 2013. O experimento foi conduzido no município de Itiquira - MT, sendo que em cada ponto coletou-se amostras de raízes e solo, com amostragem em maio e novembro. A análise nematológica das raízes e solo foi efetuada conforme metodologias especifica. A análise estatística foi realizada em Delineamento Inteiramente Casualizado, com esquema fatorial $5 \times 2$ e 15 repetições. Os dados de infestações foram transformadas em $\log (\mathrm{X}+1)$ e submetidos à análise de variância e, quando significativos, as médias comparadas pelo teste de Tukey a $5 \%$ de probabilidade. As populações foram altas em todos os clones, sendo que as infestações, nas raízes e no solo, em maio foram maiores do que em novembro. As infestações de $M$. exigua nas raízes e no solo, médias entre os dados de maio e novembro nos clones/ enxertos avaliados, não apresentaram diferença significativa entre si pelo teste de Tukey, porém, houve diferença significativa pelo mesmo teste entre as infestações médias dos meses.de maio e novembro.

Palavras-chave: Hevea brasiliensis, Nematoide das galhas, Lasiodiplodia theobrome.

\section{ABSTRACT}

Pezzoni Filho, J.C.; Brida, A.L.; Takata, W.H.S.; Wilcken, S.R.S.; Furtado, E.L. Infestations of Meloidogyne exigua in Asian rubber clones in Mato Grosso, Brazil. Summa Phytopathologica, v.45, n.3, p.326-331, 2019.

Among the phytosanitary problems of rubber tree cultivation is the incidence of root knot, more specifically Meloidogyne exigua race 3, demonstrating great importance for the crop, which was verified in the present evaluation since it led to crop abandonment. In this experiment, infestation of M. exigua was evaluated in rubber tree crop, without rootstock identification, in the roots and soil and in clones GT 1, PR 255, PB 235, PB 217 and RRIM 600; infestations were verified between clones/grafts and among the populations evaluated in two periods of 2013. The experiment was conducted in the municipality of Itiquira - MT, where samples of roots and soil were collected at each point in May and November. The nematological analysis of roots and soil was carried out according to specific methodologies. Statistical analysis was performed in a completely randomized design, with $5 \times 2$ factorial scheme and 15 replicates. Infestation data were transformed into $\log (\mathrm{X}+1)$ and subjected to analysis of variance and, when significant, means were compared according to Tukey's test at $5 \%$ probability. The populations were high for all clones, and the infestations in the roots and soil in May were higher than those in November. The infestations of $M$. exigua in the roots and soil, means between data from May and November for evaluated clones/grafts, did not present significant differences according to Tukey's test, but there was a significant difference according to the same test between the mean infestations of May and November.

Keywords: Hevea brasiliensis, Root-knot, Lasiodiplodia theobrome

A seringueira pertence ao gênero Hevea, família Euphorbiaceae, apresentando ocorrência na Amazônia brasileira, Bolívia, Colômbia, Peru, Venezuela, Equador, Suriname e Guiana. O gênero compreende onze espécies, onde a Hevea brasiliensis (Wild. ex. Adr. de Juss.) Muell. Arg. é a plantada comercialmente, pois demonstra maior produtividade de látex em relação as demais espécies (19). Sua exploração econômica está baseada na sangria para a extração do látex, onde os vasos laticíferos da casca são cortados para liberarem a borracha natural (15).

Seu plantio comercial, chamado de heveicultura, apresenta problemas fitossanitários, dentre estes, deve ser citado o nematoide das galhas (Meloidoginose). O ciclo de vida do nematoide das galhas presente na raiz apresenta a massa de ovos na superfície da raiz, e com condições favoráveis ocorre a eclosão dos ovos, originando o Juvenil infectivo (J2). Posteriormente penetra a raiz e se desloca para o cilindro vascular e neste sítio de alimentação, ocorre a indução da formação das células gigantes. Neste local, o Meloidogyne sofre ecdises do J2 $\rightarrow \mathrm{J} 3$ $\rightarrow \mathrm{J} 4$, terminando o ciclo com a fêmea adulta depositando a massa de ovos na superfície da raiz (24).

Meloidogyne exigua possui três raças. A raça 1 infecta o pimentão e o cafeeiro; a raça 2 parasita o pimentão, cafeeiro e tomateiro, e a raça 
3 é específica da seringueira $(5,13)$. O M. exigua predispõem a planta ao fungo oportunista Botryodiplodia theobromae Pat. (=Lasiodiplodia theobrome (Pat.) Griff. \& Maubl.), sendo este nematoide responsável pela redução do vigor das plantas, o qual causou a morte de cerca de 3\% das árvores de uma plantação em Mato Grosso, entre os anos de 1979 e 1986 (16).

Este nematoide causou reduções na altura e no diâmetro dos porta-enxertos GT 1, PB 235, PB 217, RRIM 501, PR 255, IAN 873 , RRIM 600 e TJ 1, onde todos foram intolerantes e suscetíveis à este fitoparasita (14). Os porta-enxertos PB 235, RRIM 600 e IAN 873 apresentaram pequenas galhas e massas de ovos, consideradas resistentes a Meloidogyne javanica, entretanto suscetíveis a M. exigua. (8). Também causaram problemas em plantios nos clones RRIM 600, PB 235, PB 217, IAN 873 e IAN 717 (16, 3). Infestações foram relatadas em plantios no município de Goianésia - GO, Prata-MG e Nanuque ES, além de diversos municípios de São Paulo (26). Com a utilização de identificação morfológica, através do sequenciamento da região do DNA ribossomal D2/D3O, Wilcken et al. (25) confirmaram a presença do $M$. exigua em plantio na região de Prata-MG.

Populações de $M$. exigua foram verificadas em raízes de $H$. brasiliensis no Estado do Pará e Amazonas $(17,18)$ sugerindo serem nativas da região e que o $M$. exigua ocorre endemicamente na Amazônia e Pré-Amazônia. Sharma et al. (20) encontraram altas infestações de Meloidogyne spp. em Rondonópolis, MT, causando severos danos em seringal de diferentes idades, e citaram que a gradagem favorece a dispersão e o aumento do nível de infestação do nematoide.

O objetivo do trabalho foi avaliar a infestação de $M$. exigua em plantio de seringueira, nas raízes e no solo, nos clones/ enxertos GT 1, PR 255, PB 235, PB 217 e RRIM 600 e verificar se ocorre diferença estatística nas infestações entre os clones e entre duas épocas do ano.

\section{MATERIAL E MÉTODOS}

A área de estudo localizou-se no município de Itiquira-MT, que pertenceu à Plantações Michelin Mato Grosso, com 5.907 ha, em seringal com idades entre 13 e 34 anos, identificados com os clones/ enxertos GT 1, PR 255, PB 235, PB 217 e RRIM 600, com áreas de 1.529 ha, 1.251 ha, 1.203 ha, 1.044 ha e 880 ha, respectivamente. As coordenadas geográficas do extremo sul do plantio foram $17^{\circ} 26^{\prime} 17,73^{\prime}$ "

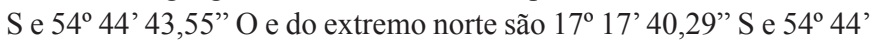
28,6" O, na bacia do Rio Paraguai. As idades das árvores dos clones do local de estudo, no ano de 2013, foram entre 23 e 34 anos (clone GT 1), 13 à 30 anos (PR 255), 23 à 31 anos (PB 235), 23 à 31 anos (PB 217) e 23 à 34 anos (RRIM 600). Em nenhum deles foi possível a identificação do porta enxerto.

Os solos da área de estudo são classificados como Latossolo Vermelho Distrófico típico - LVd e em menor proporção, como Neossolo Quartzarênico Órticos típicos - RQo, de acordo com classificação da Embrapa (7). Os pontos amostrais foram distribuídos em toda a área experimental em grade irregular devido ao fato da distribuição do plantio dos clones apresentar-se de forma irregular e a infestação ocorrer em todo o plantio. Em cada ponto amostral foram coletadas amostras de $40 \mathrm{~g}$ de raízes de seringueira, em média, e 150 $\mathrm{ml}$ de solo em maio e em novembro. A amostra de solo localizou-se ao redor das raízes coletadas, com profundidade média de $0,10 \mathrm{~m}$.

A análise nematológica das amostras de raízes e de solo foi realizada conforme a metodologia proposta por Coolen \& D' Herde (6) e Jenkins (11), respectivamente. Após a extração dos nematoides, foram efetuadas as contagens da população total de $M$. exigua na lâmina de Peters, sob microscópio de luz. Para a infestação nas raízes foi considerado o número de indivíduos de $M$. exigua em $10 \mathrm{~g}$ de raízes e para o solo foi a quantidade de indivíduos em $100 \mathrm{ml}$ de solo, sendo extrapolada para o volume de $250 \mathrm{ml}$ de solo. Na contagem de indivíduos, nas amostras de raízes e solo, foram consideradas as formas de ovo e juvenil de segundo estádio (J2).

A análise foi conduzida em Delineamento Inteiramente Casualizado, com esquema fatorial 5 × 2 (clones/ tratamentos x épocas do ano) e 15 repetições, totalizando 75 amostras. Os cinco tratamentos foram compostos pelos clones de copa GT 1, PR 255, PB 235, PB 217 e RRIM 600 em duas diferentes épocas do ano. Os valores de infestação, de número de indivíduos $\mathrm{J} 2$ e ovos em $10 \mathrm{~g}$ de raiz e em $250 \mathrm{ml}$ de solo foram transformados em $\log (\mathrm{X}+1)$ e submetidos à análise de variância e quando significativos, as médias comparadas pelo teste de Tukey a $5 \%$ de probabilidade.

\section{RESULTADOS E DISCUSSÃO}

As infestações ocorreram de 167 até 200.615 nematoides (ovos e juvenis J2) em $10 \mathrm{~g}$ de raízes em maio, no clone PR 255 e PB 217, respectivamente (Tabela 1). Os dados encontrados na presente avaliação são semelhantes ao encontrado por Bernardo et al. (3), que encontraram infestação de 61.824 juvenis/ $5 \mathrm{~g}$ de raízes, em levantamento realizado no município de São José do Rio Claro, MT. Nos cinco clones avaliados ocorreram altas populações de $M$. exigua, demonstrando que o patógeno apresenta agressividade alta. Nas coletas de campo do presente experimento, verificou-se presença de plantas de seringueira mortas e debilitadas, com a redução da produtividade de látex esperada por planta, devido à alta incidência do $M$. exigua, levando à erradicação do plantio e substituição por culturas anuais

No presente trabalho, o clone/ enxerto RRIM 600 apresentou população de até 197.918 nematoides em $10 \mathrm{~g}$ de raiz (Tabela $1 \mathrm{e}$ Figura 1), demonstrando suscetibilidade ao M. exigua, que também foi comprovada por Silveira (21). Este autor citou que o clone RRIM 600 é altamente suscetível aos nematoides das galhas. Santos et al. (16) e Fonseca et al. (8) citaram que este clone é suscetível ao M. exigua e resistente ao M. javanica. Fonseca et al. (9), estudando o clone RRIM 600 , inocularam 1.000 juvenis J2 e, após 10 dias, verificaram a presença de células gigantes jovens.

Em novembro, a população de nematoides em $10 \mathrm{~g}$ de raízes variou de 0, no enxerto RRIM 600, até 75.250, no enxerto PB 235 (Tabela 1). Desta forma houve uma redução de $62,49 \%$ da maior infestação em maio em relação a novembro. Em maio, as plantas dos 5 clones ainda tem considerável vigor vegetativo, devido ao fato de terem seu metabolismo influenciado pela época do verão. Com isso a população de nematoide aumenta e se dissemina, pois tem condições favoráveis, ou seja, umidade no solo, e temperaturas dentro da faixa de 25 a $30^{\circ} \mathrm{C}$, que conforme Blum (4) é a faixa ideal para o metabolismo dos nematoides das galhas. Fato semelhante foi constatado por Souza et al. (22) em M. exigua no cafeeiro, que apresentou maiores infestações e número de galhas nas raízes no período chuvoso e no solo ocorreu queda na população de juvenis.

Fonseca et al. (8) avaliaram plantas de seringueira em vaso com inoculação de 6.000 juvenis J2 no clone PB 235, RRIM 600 e IAN 873, sendo que os 3 clones foram classificados como suscetíveis ao M. exigua. Esta avaliação confirmou a suscetibilidade encontrada na avaliação do presente experimento, onde foi encontrada população 
Tabela 1. Número de amostras, médias de indivíduos de M. exigua nas raízes e no solo e variação populacional nos 5 clones/ enxertos de seringueira (H. brasiliensis).

\begin{tabular}{|c|c|c|c|c|c|}
\hline $\begin{array}{l}\text { Clones/ } \\
\text { enxertos }\end{array}$ & $\begin{array}{c}\text { Meses/ local } \\
\text { amostrado }\end{array}$ & $\begin{array}{l}\text { Número de } \\
\text { amostras }\end{array}$ & $\begin{array}{c}\text { Média de nematoides/ } \\
10 \mathrm{~g} \text { de raízes }\end{array}$ & $\begin{array}{c}\text { Média de nematoides/ } \\
250 \mathrm{~mL} \text { de solo }\end{array}$ & $\begin{array}{c}\text { Variação populacional } \\
\text { (ovos e J2) }\end{array}$ \\
\hline \multirow{4}{*}{ GT 1} & Maio - raiz & 29 & 52.031 & - & $2.640-159.840$ \\
\hline & Novembro - raiz & 27 & 4.470 & - & $300-13.860$ \\
\hline & Maio - solo & 29 & - & 2.194 & $0-28.000$ \\
\hline & Novembro - solo & 27 & - & 132 & $0-611$ \\
\hline \multirow{4}{*}{ PB 217} & Maio - raiz & 29 & 42.017 & - & $1.620-200.615$ \\
\hline & Novembro - raiz & 24 & 4.120 & - & $480-10.120$ \\
\hline & Maio - solo & 29 & - & 781 & $0-6.240$ \\
\hline & Novembro - solo & 24 & - & 119 & $0-534$ \\
\hline \multirow{4}{*}{ PB 235} & Maio - raiz & $25^{* *}$ & 42.757 & - & $3.450-169.684$ \\
\hline & Novembro - raiz & 24 & 7.799 & - & $1.380-75.250$ \\
\hline & Maio - solo & 27 & - & 2.050 & $0-32.400$ \\
\hline & Novembro - solo & 24 & - & 82 & $0-293$ \\
\hline \multirow{4}{*}{ PR 255} & Maio - raiz & 22 & 45.991 & - & $167-134.400$ \\
\hline & Novembro - raiz & 12 & 4.437 & - & $940-12.600$ \\
\hline & Maio - solo & 22 & - & 2.122 & $0-24.050$ \\
\hline & Novembro - solo & 12 & - & 172 & $0-700$ \\
\hline \multirow{4}{*}{ RRIM 600} & Maio - raiz & $26^{*}$ & 46.284 & - & $5.400-197.918$ \\
\hline & Novembro - raiz & 25 & 6.170 & - & $0-27.690$ \\
\hline & Maio - solo & 27 & - & 1.228 & $0-8.400$ \\
\hline & Novembro - solo & 25 & - & 165 & $0-763$ \\
\hline
\end{tabular}

Números de amostras de raízes, em maio e novembro, com * representa que ocorreu perda de uma amostra e ** representa perda de duas amostras durante o processo de análise nematológica.
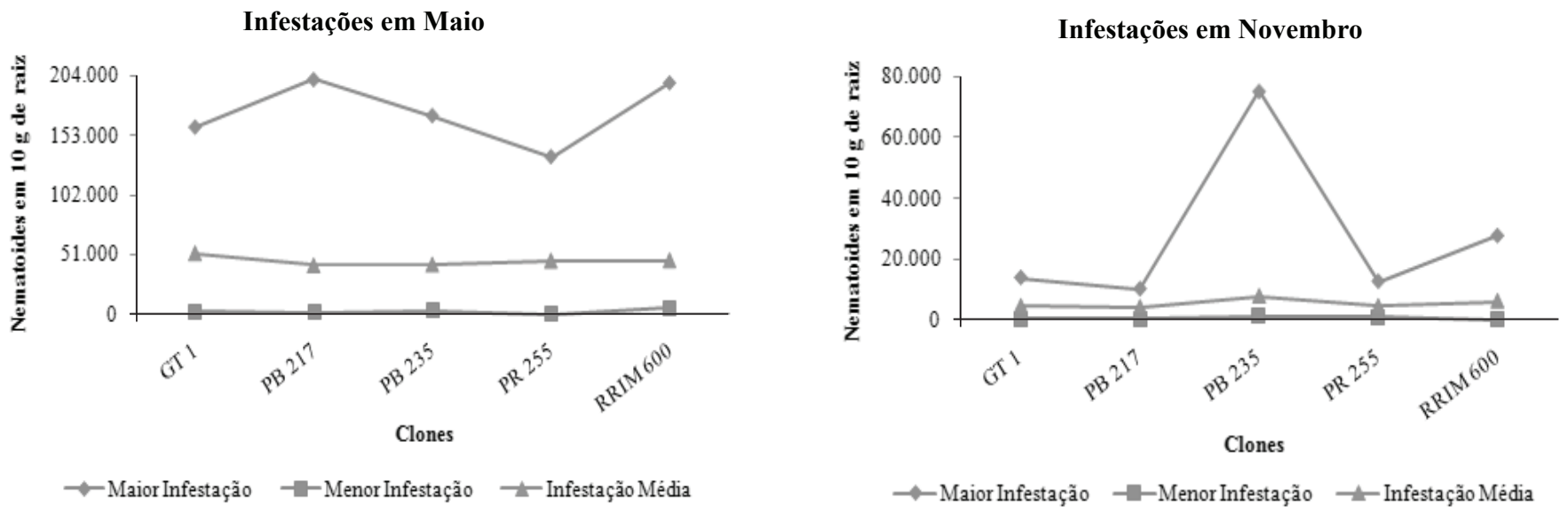

Figura 1. Comparações de infestações nas raízes (10 g) dos 5 clones, em maio e novembro.

máxima de 169.684 nematoides e média populacional de 42.757 nematóides em $10 \mathrm{~g}$ de raízes do clone PB 235, em maio (Figura 1), enquanto que a média de infestação no solo foi de 2.050 nematoides em $250 \mathrm{ml}$ de solo (Figura 2).

No segundo semestre os 5 clones/ enxertos apresentaram infestações médias variando de 7.799 nematoides em $10 \mathrm{~g}$ de raízes, no clone PB 235, até 4.120 nematoides em $10 \mathrm{~g}$ de raízes, clone PB 217. Os valores máximos e mínimos foram $85,01 \%$ e 90,19\% (Tabela 1) abaixo daqueles encontrados em maio, respectivamente (Figura 1). Na hibernação ocorre a morte de parte das raízes da planta e determinadas populações de $M$. exigua morrem junto, sendo uma forma de controle natural do nematoide pela planta.
As reduções nas infestações entre maio e novembro foram 91,41\%, $90,19 \%, 81,76 \%, 90,35 \%$ e $86,67 \%$ para os clones/ enxertos GT 1, PB 217, PB 235, PR 255 e RRIM 600, respectivamente (Figura 1). Esta redução de infestação ocorreu devido a influência do período de hibernação dos cinco clones e o período com baixa ou nenhuma precipitação, dentre outros fatores. Conforme argumentou Starr (23), observou que a baixa umidade do solo inibiu a eclosão do J2 antes de afetar o desenvolvimento embrionário, possibilitando maior população de ovos com J2.

Na região de Itiquira, MT, a época de desfolha dos clones ocorre entre maio e julho, quando a planta fica com seu metabolismo reduzido. O período com pouca pluviosidade é simultâneo à desfolha natural da 
Infestações em Maio

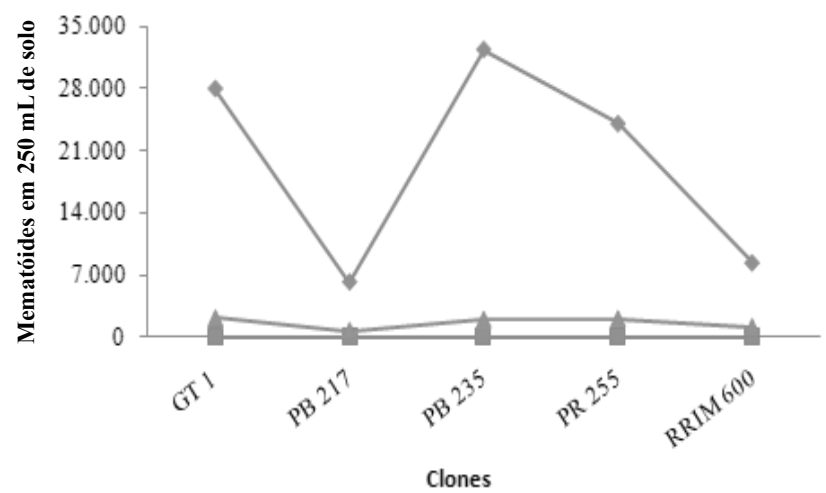

$\rightarrow$ Maior Infestação $\quad-\square$-Menor Infestação $\quad \leftarrow$-Infestação Média
Infestações em Novembro

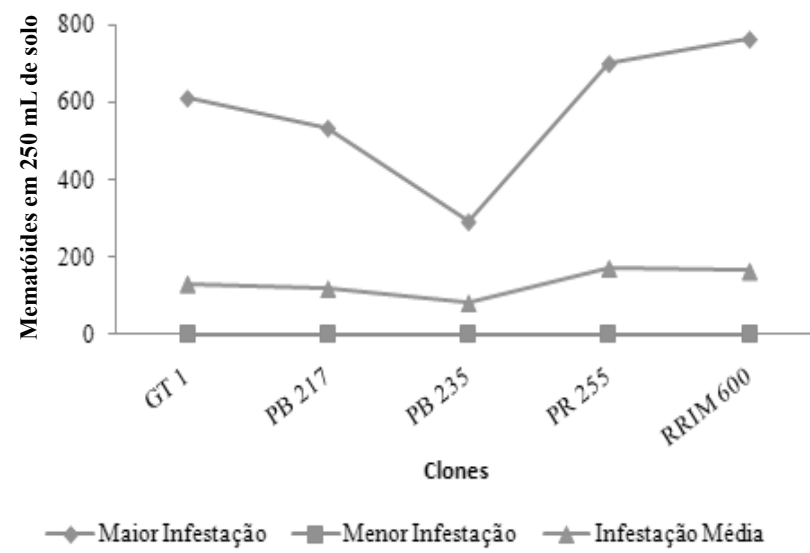

Figura 2. Comparação das infestações no solo $(250 \mathrm{~mL})$ nos 5 clones, em maio e novembro.

seringueira, sendo dois importantes fatores na redução da população de nematoides, com função estratégica para o controle populacional, reduzindo o número de nematoides nas plantas de forma considerável.

Após a reenfolha, as raízes que permaneceram vivas, infestadas de nematoides, e $M$. exigua em estágio latente no solo são a fonte de inóculo para o início da infestação nas raízes que crescem depois da hibernação, no período chuvoso do ano. Desta forma, estas que se encontravam infestadas passam a ter maiores populações quando se aproximam do período antes da desfolha natural, no ano seguinte. Este fato de redução das raízes resulta na diminuição da população de nematoides evidenciada no solo, entre os meses de maio e novembro, pois a fêmea deposita os ovos na superfície das raízes e com a eclosão, os juvenis migram para o solo, podendo ou não infectar a raiz em que a mãe está parasitando.

Em amostras de um mesmo clone plantado no mesmo ano, houve infestações muito discrepantes. Desta forma, as infestações não demonstraram correlação com a idade. Um fator que deve ser considerado é a infestação inicial presente nas mudas dos diferentes clones, pois as plantas eram produzidas em viveiro no próprio local, com utilização de solo contaminado pelo M. exigua. Porém, neste caso não pôde ser verificado o seu nível populacional inicial.

A diminuição da população no solo têm as mesmas explicações determinadas para aquelas das raízes, ou seja, desfolha anual na seringueira. No período de senescência ocorre redução no sistema radicular com diminuição da infestação nas raízes, as quais seriam a fonte de inoculo de juvenis, pois na sua superfície estão boa parte dos ovos que eclodem e, posteriormente, seus juvenis migram para o solo. Além deste fato, deve ser citada a diminuição da umidade no solo no período seco do ano, concordando com Souza et al. (22), que citou que o M. exigua em plantio de café demonstrou maiores infestações e números de galhas nas raízes no período chuvoso do ano.

As infestações de $M$. exigua, médias entre os dados de maio e novembro, encontradas em $10 \mathrm{~g}$ de raiz e em $250 \mathrm{ml}$ de solo entre os clones de copa PB 217, PB 235, RRIM 600, GT 1 e PR 255 não apresentaram diferença significativa $(\mathrm{p}>0,05)$ entre si pelo teste de Tukey a $5 \%$ (Tabela 2). Os valores médios de infestações foram elevados, variando de $24.855,65$ nematoides até $31.324,87$ nematoides em $10 \mathrm{~g}$ de raiz. Estas infestações altas provavelmente interferem no adequado desenvolvimento das plantas e consequentemente na
Tabela 2. Numero médio de infestações de 5 clones de seringueira $(H$. brasiliensis) em $10 \mathrm{~g}$ de raízes e $250 \mathrm{ml}$ de solo

\begin{tabular}{lllcc}
\hline \multirow{2}{*}{ Clone/ enxerto } & \multicolumn{3}{c}{ Infestações $^{1}$} \\
\cline { 2 - 5 } PB 217 & $24.855,65$ & a & 481,38 & Solo \\
PB 235 & $25.634,88$ & a & $1.123,64$ & a \\
RRIM 600 & $26.620,04$ & a & 717,24 & a \\
GT 1 & $29.100,09$ & a & $1.199,73$ & a \\
PR 255 & $31.324,87$ & a & $1.433,61$ & a \\
\hline F & $0,20 \mathrm{~ns}$ & & $1,50 \mathrm{~ns}$ & \\
cV (\%) & 12,18 & 34,48 & \\
\hline ': Médias com mesma letra não diferem entre si pelo teste de Tukey a 5\% de probabilidade. \\
ns: Não significativo a 5\% de probabilidade pelo teste F.
\end{tabular}

produção de látex.

Nas duas épocas estudadas, maio e novembro, as infestações apresentaram diferença significativas entre si, conforme pode ser observado na Tabela 3, onde a infestação média nas raízes, dos cinco clones, em maio foi 8,37 vezes maior do que novembro. Para as médias de infestações no solo, em novembro ocorreu diminuição aproximada de 12,7 vezes em relação ao mês de maio (Tabela 3 ).

$\mathrm{Na}$ seringueira o máximo de população encontrada foi em maio, mas pode ser que nos meses precedentes e seguintes a maio ocorram infestações altas, porém, este fato precisa ser investigado em trabalhos futuros. Almeida \& Campos (2) verificaram que o número de juvenis de $M$. exigua no solo de cafezal foi sempre alto no período de abril a outubro com o pico máximo em junho, coincidindo com a época inadequada à emissão de raízes novas. Comparando-se com a seringueira, em maio começa a desfolha natural da planta, nos clones mais precoces, sendo que pode ser que ocorreu a redução das raízes da planta como aconteceu no cafeeiro e, desta forma, houve a redução natural da população. No plantio foram observados locais com reboleiras de plantas mortas, onde, pelos sintomas apresentados, provavelmente foram devido ao parasitismo pelo M. exigua. As plantas demonstravam seca dos ponteiros com morte descendente. 
Tabela 3. Médias de infestações dos 5 clones de seringueira $(H$. brasiliensis), nas raízes e no solo, para os meses de maio e novembro.

\begin{tabular}{lcccc}
\hline Época & Raiz & \multicolumn{2}{c}{ Solo } \\
\hline Maio & $45.889,28$ & a & $1.652,78$ & a \\
Novembro & $5.484,25$ & b & 130,11 & b \\
\hline $\mathrm{F}$ & $198,17 * *$ & $61,38^{* *}$ \\
\hline $\mathrm{F}$ (int) & $0,55 \mathrm{~ns}$ & \multicolumn{2}{c}{$0,22 \mathrm{~ns}$} \\
\hline cv (\%) & 12,18 & 34,48 \\
\hline $\begin{array}{l}\text { : Médias com mesma letra não diferem entre si pelo teste de Tukey a 5\% de probabilidade. } \\
\text { **: Significativo a 5\% de probabilidade pelo teste F; ns: Não significativo a 5\% de } \\
\text { probabilidade pelo teste F. }\end{array}$
\end{tabular}

Para o teste F, nos dois locais com infestações (raízes e solo), houve diferença estatística significativa entre as amostragens (Tabela 3). A diferença estatística apresentada nas infestações entre maio e novembro, ou seja, redução de sua população, pode ser devido ao período de hibernação dos clones, conforme já foi mencionado.

A maior quantidade de nematoides ocorreu em maio, em ambas as condições (raiz e solo), ocorrendo após o período chuvoso e altas temperaturas, fatores determinantes à reprodução descontrolada do nematoide. Fatores que podem estar relacionados ao aumento das infestações são a ausência de inimigos naturais e de controle efetivo, pois a monocultura pode selecionar poucos nematoides daqueles que estavam no solo, entre eles o M. exigua.

Os diferentes níveis de infestações, em maio e novembro, encontrados nos clones avaliados foram semelhantes aqueles encontrados em cafeeiro por Almeida et al. (1). Estes autores encontraram as maiores densidades populacionais de $M$. exigua no solo ocorrendo de abril a julho e as menores de dezembro a março. Assim, pode-se considerar que para realizar medidas de controle populacional, quando forem desenvolvidos produtos nematicidas eficientes, o ideal seria utilizar este período após o reenfolhamento para suas aplicações no plantio, uma vez que com menor infestação nas plantas permite melhor resposta de controle.

Para o plantio, com início no ano de 1979, a rica e diversa vegetação do Cerrado comum na área foi substituída pelo monocultivo de Hevea, provavelmente ocorrendo a seleção do $M$. exigua fitoparasita da seringueira nativo desta região conforme descreveu Santos (17). Sua população aumentou de forma descontrolada, talvez por desequilíbrio com seus inimigos naturais.

A forma de manejo da plantação com gradagens e movimentação dos maquinários pode ter disseminado o nematoide no seringal, inclusive para locais onde possivelmente estava ausente. Sharma et al. (20) citou que a gradagem favorece a dispersão e o aumento do nível de infestação do nematoide.

Os danos ocasionados pela alta infestação dos nematoides nas plantas apresentam grande importância, Gonçalves et al. (10) citaram que é necessário considerar as perdas indiretas causadas pelo parasitismo dos nematoides como a menor tolerância ao frio e à seca e, perda parcial na eficiência de utilização de alguns insumos. Adicionalmente, deve ser considerada a suscetibilidade aumentada a fungos secundários, associada à infestação de nematóide.

Devido a baixa produtividade do seringal em decorrência da alta infestação de $M$. exigua o mesmo foi erradicado e susbstituído por platanção de soja.

\section{REFERÊNCIAS}

1. Almeida, V.F.; Campos, V.P.; Lima, R.D. Flutuação populacional de Meloidogyne exigua na rizosfera do cafeeiro. Nematologia Brasileira, Piracicaba, v.11, n.1, p.159-175, 1987.

2. Almeida, V.F.; Campos, V.P. Alternância de culturas e sobrevivência de $\mathrm{Me}$ loidogyne exigua em áreas de cafezal infestado e erradicado. Nematologia Brasileira, Piracicaba, v.15, n.1, p.30-42, 1991.

3. Bernardo, E.R.A.; Santos, J.M.; Silva, R.A.; Cassetari Neto, D.; Santos, S.S.; Delmadi, L.; Rocha, V.F. Levantamento de Meloidogyne exigua na cultura da seringueira em São José do Rio Claro, MT, Brasil. Ciência Rural, Santa Maria, v.33, p.157-159, 2003. Disponível em: <http://www.scielo.br/ pdf/cr/v33n1/14159.pdf $>$. Acesso em: 05 jan. 2014.

4. Blum, L.E.B. Fitopatologia: o estudo das doenças de plantas. Brasília, DF: Otimismo, 2006. 258p.

5. Carneiro, R.M.D.G.; Almeida, M.R.A. Caracterização isoenzimática e variabilidade intraespecífica dos nematoides de galhas do cafeeiro no Brasil. In: Simpósio de Pesquisa dos Cafés do Brasil, 1, 2000, Poços de Caldas. Resumos. Poços de Caldas: Embrapa Café, 2000. p.280-282. Disponível em: <http://www.sapc.embrapa.br/arquivos/consorcio/spcb_anais/simposio1/Doencas31.pdf> Acesso em: 24 mai. 2019.

6. Coolen, W.A.; D' Herde, C.J.A. Method for the quantitative extraction of nematodes from plant tissue. Ghent: State of Nematology and Entomology Research Station, 1972. 77p.

7. Embrapa. Sistema brasileiro de classificação de solos. 3.ed. Brasília, DF: Embrapa Informação Tecnológica, 2013.

8. Fonseca, H.S.; Jaehn, A.; Silva, M.F.A. Reações de porta enxertos de seringueira (Hevea brasiliensis) a Meloidogyne javanica e M. exigua. Nematologia Brasileira, Brasília, DF, v.23, n.2, p.9-14, 1999. Disponível em: $<$ http://docentes.esalq.usp.br/sbn/nbonline/ol\%20232/9-14\%20pb. pdf $>$. Acesso em: 21 abr. 2014.

9. Fonseca, H.S.; Ferraz, L.C.C.B.; Machado, S.R. Ultraestrutura comparada de raízes de seringueira parasitadas por Meloidogyne exigua e $M$. javanica. Nematologia Brasileira, Brasília, DF, v.27, n.2, p.199-206, 2003. Disponível em: $<$ http://docentes.esalq.usp.br/sbn/nbonline/ol\%20272/199-206\%20 pb.pdf>. Acesso em: 12 mar. 2014.

10. Gonçalves, W.; Ramiro, D.A.; Gallo, P.B.; Giomo, G.S. Manejo de nematóides na cultura do cafeeiro. In: Reunião Itinerante de Fitossanidade do Instituto Biológico-Café, 10., 2004, Mococa. Anais. Mococa: Instituto Biológico, 2004. p.48-66

11. Jenkins, W.R. A rapid centrifugal - flotation technique for separating nematodes from soil. Plant Disease Report, St. Paul, v.48, p.692, 1964.

12. Moraes, V.H.F. Sugestões para uniformização da metodologia de estudo da fenologia foliar da seringueira. Manaus: EMBRAPA-CNPSD, 1983. (Série Documentos, 1). Disponível em: $<$ http://ainfo.cnptia.embrapa.br/digital/bitstream/item/53173/1/Documentos-01.pdf $>$. Acesso em: 15 jan. 2014.

13. Muniz, M.F.S.; Campos, V.P.; Castagnone-Sereno, P.; Castro, J.M.C.; Almeida, M.R.A.; Carneiro, R.M.D.G. Diversity of Meloidogyne exigua (Tylenchida: Meloidogynidae) populations from coffee and rubber tree. Nematology, Leiden, v.10, p.897-910, 2008. Disponível em: <http://www. alice.cnptia.embrapa.br/bitstream/doc/160970/1/OPB1942.pdf>. Acesso em: 22 dez. 2015.

14. Paes-Takahashi, V.S.; Soares, P.L.M.; Guiducci, E.P.; Brito, P.F.; Carneiro, F.A.; Ferreira Junior, R. Reação de porta-enxertos de seringueira a Meloidogyne exigua e a Pratylenchus brachyurus. Nematropica, v.45, n.2, 2015. Disponível em: <http://journals.fcla.edu/nematropica/article/ view/87385/84218>. Acesso em: 05 jan. 2016.

15. Rajagopal, R.; Vijayakumar, K.R.; Thomas K.U.; Karunaichamy, K. Effect of judicious ethephon application on yield response of Hevea brasiliensis (Clone RRII 105) under $1 / 2 \mathrm{~S} \mathrm{~d} / 3$ 6d/7 tapping system. Journal of Rubber Research, Kuala Lumpur, v.7, p.138-147, 2004.

16. Santos, J.M.; Matos, C; Barré, L.; Ferraz, S. Meloidogyne exigua, sério patógeno da seringueira nas plantações E. Michelin, em Rondonópolis, MT. In: Congresso Brasileiro de Nematologia, 16, 1992, Lavras. Anais. Lavras, MG: Sociedade Brasileira de Fitopatologia, 1992. v.17, p.75.

17. Santos, J.M. Meloidogyne exigua e Botryodiplodia theobromae, principais componentes bióticos de uma doença complexa da seringueira em Mato Grosso. Fitopatologia Brasileira, Brasília, DF, v.28, p.341,1995.

18. Santos, J.M. Estudos das principais espécies de Meloidogyne Goeldi que infectam o cafeeiro no Brasil com descrição de Meloidogyne goeldii 
sp. 1997. 153p. Tese (Doutorado em Proteção de Plantas) - Universidade Estadual Paulista, Botucatu.

19. Secco, R.S. A botânica da seringueira [(Hevea brasiliensis (Willd. ex Adr. Jussieu) Muell.Arg.)]. In: Alvarenga A.P.; Carmo, C.A.F.S. Seringueira. Viçosa: Epamig, 2014. p.19-42.

20. Sharma, R.D.; Junqueira, N.T.V.; Barre, L.; Rocha, V.F. Efeitos de práticas culturais na incidência de Meloidogyne sp, em seringueira de cultivo. Fitopatologia Brasileira, Brasília, DF, v.17, n.2, p.226, 1992.

21. Silveira, S.G.P. Nematoides associados à cultura da seringueira (Hevea spp.). In: Medrado, M.J.S.; Bernardes, M.S.; Costa, J.D.; Martins, A.N. (Ed.). Formação de mudas e plantio de seringueira. Piracicaba: Escola Superior de Agricultura "Luiz de Queiroz"-USP, 1992. p.78-82.

22. Souza, S.E.; Souza, L.H.; Santos, F.S.; Silva, R.V. Flutuação populacional de Meloidogyne exigua (Goeldi, 1887) em cafeeiros no município da Barra da Choça - BA, Bahia Agrícola, Salvador, v.2, n.3, p. 77-81, nov. 1998. Disponível em: <http://www.seagri.ba.gov.br/sites/default/files/pesquisa_agricolaV2N3.pdf>. Acesso em: 11 out. 2014.

23. Starr, J.L. Recovery and longevity of egg masses of Meloidogyne incognita during simulated winter survival. Journal of Nematology, Leiden, v.25, n.2, p.244-248, 1993. Disponível em: <https://www.ncbi.nlm.nih.gov/pmc/ articles/PMC2619360/pdf/244.pdf>. Acesso em: 29 jul. 2016.

24. Williamson, V.M.; Gleason, C.A. Plant-nematode interactions. Current Opinion in Plant Biology, v.6, n.4, p.327-333, 2003. Disponível em: $<$ http://www.ufv.br/dbv/pgfvg/BVE684/htms/pdfs_revisao/estresse/ Plant nematode\%20interactions.pdf $>$. Acesso em: 24 ago. 2016.

25. Wilcken, S.R.S.; Firmino, A.C.; Furtado, E.L. Detecção de Meloidogyne exigua em plantas de seringueira em Prata-MG. In: Congresso Paulista de Fitopatologia, 36., 2013 São Paulo. Anais. São Paulo: Sociedade Paulista de Fitopatologia, 2013. v.39, p.251. Disponível em: <http:// www.summanet.com.br/summanet-site/congressos/2013/Busca.html>. Acesso em: 02 jun. 2016

26. Wilcken, S.R.S.; Gabia, A.A.; Brito, P.F.; Furtado, E.L. Nematoides fitoparasitas em seringais do Estado de São Paulo. Summa Phytopathologica, Botucatu, v.41, n.1, p.54-57, 2015. Disponível em: <http:// www.scielo.br/pdf/sp/v41n1/0100-5405-sp-41-01-00054.pdf>. Acesso em: 09 fev. 2016. 